colleges; but in some ways they have to pay the price, for national pride and aspirations are not satisfied with the meagre provision for higher education that is warranted in view of the poor schools. These latter could do with a period of patient quiet to develop ; but, as it is, good teachers who could not be spared had been diverted to sixth-form work. In the end, this may prove a good thing, for sometimes it pays to be stretched educationally, and the schools will be compensated by receiving back a stream of good teachers. But for the period ahead in the development of secondary education, Sir James said that two things are necessary : schools must keep up standards in their lower forms and improve their English, and, if a rapid expansion of secondary education comes, good staffs must not be dispersed. A few good schools must be kept going while standards are being raised elsewhere.

Miss F. Gwilliam, assistant educational adviser to the Secretary of State for the Colonies, then spoke on "The Challenge to Teacher-Training". She asked three questions : Who are the teachers, what standards are they trying to preserve, and how are they meeting the challenge? The teachers themselves, said Miss Gwilliam, have greatly varying backgrounds and qualifications, and often they were of many nationalities. There are Austrian nuns, American missionaries, teachers from Britain who have gone out through the Overseas Appointments Bureau, the personnel of the Colonial Education Service and the local teachers themselves. All these, said Miss Gwilliam, are the teachers. The standards they are seeking to preserve, she thought, are of four sortsacademic, personal, professional and civic standards -and to maintain and improve them constitutes the challenge to teacher-training. In the different territories of the British Colonies this challenge is being met in a number of ways : local training colleges are being built in increasing numbers, scholarship funds are being provided to send students to Britain for training, and 'on-the-spot' vacation courses are being run for practising teachers. The teachers themselves are taking full advantage of these facilities, and in Cyprus, for example, 80 per cent of primary school teachers take part in unpaid, voluntary vacation courses. The in-service training schemes of the Gold Coast and the Malayan training colleges in Britain are other outstanding examples of the way in which the challenge is being met. Behind all these efforts, said Miss Gwilliam, lies the educational resources of Britain in inspiration, advice and help.

The symposium was brought to an end by Mr. Philip Sherlock, vice-principal of the University College of the West Indies, who spoke on "National Aspirations". Speaking with great eloquence and clarity, Mr. Sherlock, himself a West Indian, reminded his audience that Britain had long had a well. developed sense of nationhood. 'This the West Indies lacks. The great task there is to bring together a great variety of strains and races and to build from them a common nation. They have to fashion a new society, unlike the Gold Coast and Nigeria, who are seeking to rebuild an old one. It is in this task of nation-building that the contribution of the West Indies to the world and human understanding lies, for to do this successfully means a great emphasis on human relationships, and perhaps in this the West Indies may have something to offer others.

Mr. Sherlock paid great tribute to Britain for its help and foresight in setting up the new University College of the West Indies, for this, he said, is basic to the whole task they have in hand. The West Indies and the United Kingdom now stand as partners in the great enterprise of finding new patterns of social development. But this, he emphasized, is not a one-way process. Both sides will profit. The West Indies wants from Britain advice on an expanding secondary school system, on teacher-training, library services and other matters, and in roturn Britain might profit from the lessons learnt in what is a tremendous, dynamic move forward by the peoples of the Caribbean.

After each symposium there was a discussion in which the audience participated. Contributions were made by county education officers, professors of education, training college staff and local teachers, all of whom expressed the hope that there would be, in the future, even greater collaboration between Britain and the oversea territories in the task of promoting the latter's educational advancement.

P. C. C. Evans

\title{
PHYSIOLOGY IN THE POLAR REGIONS
}

$\mathrm{D}^{\mathrm{c}}$ URING the meeting at Sheffield of the British Association, Section I (Physiology) arranged a ession on September 4 on "Polar Physiology".

The degree of physiological adaptation to cold by man is still an unsettled problem. Although there is convincing evidence that laboratory animals can be so acclimatized that they will survive at temperatures which are lethal to control animals, chronic physiological changes in man as a result of exposure to cold have not been clearly established.

Many studies have been made in climatic chambers, in which men can stay for relatively prolonged periods in a controlled environment. Changes have been looked for in the rate of body cooling, alterations of skin temperature, changes in metabolic rate, time of onset of shivering, alteration in the peripheral blood flow and shifts of the blood volume. There has been a number of reports indicating some change in one or more of these parameters as a result of repeated exposure; but there have also been many negative reports. One of the practical difficulties of experiments in climatic chambers is to persuade subjects to stay in such chambers for long periods. 'There are indications that some significant physiological changes develop slowly over a period of many weeks or months. It is for this reason that observations have been sought on polar explorers, who spend one to two years at high latitudes. Many of the members of polar expeditions are trained scientists and can make accurate and systematic observations on them. selves. Detailed investigations of the subjects can also be made before and after prolonged sojourn in the polar regions, in laboratories in the country of origin.

Apart from low temperatures, another environmental characteristic of polar regions is of interest to 
physiologists. In high latitudes, the cycle of light and darkness varies greatly during the year, with approximately three months winter darkness and three months summer daylight. There are many biological diurnal rhythms, and it is of considerable interest to know how these rhythms in man may be affected by alteration in the pattern of day and night.

Dr. Harold Lewis, who accompanied the British North Greenland Expedition of 1952-54 as physiologist, showed a film illustrating some of the physiological problems encountered, and which demonstrated very vividly the effects of light and darkness. He also read a paper entitled "Sleep and Wakefulness Patterns in Men on a Polar Expedition". Records were kept by the members of the expedition of the hours spent in sleep each day. During the autumn and the spring, the patterns of sleep resembled those commonly observed in temperate countries. The majority went to bed between 10 p.m. and midnight and got up some eight hours later. When the sun disappeared for the long winter night, the pattern became increasingly disrupted, and the different individuals were going to bed or getting up at all hours. 'There was never a time when someone was not in bed or someone out of bed. Sleep was no longer restricted to the hours between $10 \mathrm{p} . \mathrm{m}$. and $8 \mathrm{a} . \mathrm{m}$. The intervals between periods of sleep varied greatly and so did the length of each period of sleep. A similar disruption of sleep was observed during the months of continuous daylight. These changes were observed in both years during which the expedition was in North Greenland. There did not appear to be any tendency for adaptation to the day-night pattern.

There are a number of interesting questions on sleep behaviour which can be asked as a result of these observations. Particularly during the winter months when opportunities for field-work were severely restricted, there was relatively little to do. There was no social compulsion to get out of bed at any particular hour, and opportunities for sleep were to all intents unlimited. The situation was analogous to that of 'demand' feeding in infants. Where records of the number of hours spent in sleep have been kept, in Britain and in the United States, the average is found to be approximately eight out of the twentyfour. On the North Greenland Expedition the number of hours of sleep averaged $7 \cdot 9$, and there was little difference for any month of the year. So it would appear that eight hours of sleep a day does represent a normal demand. There was no evidence that the incidence of light or darkness affected this average duration of sleep, although there was possibly an increased variation in the number of hours of sleep in twenty-four hours during the winter months.

Dr. Mary Lobban followed with a paper, "Studies on Physiological Diurnal Rhythms in Polar Regions". In the summers of 1953 and 1955 , two expeditions went from Cambridge to Spitsbergen to study the effects of prolonged periods of life with abnormal time routines upon physiological diurnal rhythms in man. In Spitsbergen the climatic conditions are such that a very high latitude can be reached with comparative ease in the summer months, and human subjects can be maintained there for considerable periods of time in isolation and under conditions of almost constant daylight and environmental temperature.

In 1953 eight subjects lived for six weeks on a 22 -hr. 'day', while in 1955 one group of seven subjects lived on a 2l-hr. 'day' and another group of five subjects lived on a 27-hr. 'day' for a similar period. In all three groups, urine samples were collected from the subjects at frequent intervals on experimental recording 'days' and a complete study was made of their diurnal excretory rhythms throughout the experimental period. On these recording 'days', diet, fluid intake and all physical activities were carefully controlled. During the 1955 expedition the diurnal variations in body temperature were also recorded.

From the results obtained on the two expeditions it would seem that rapid adaptation of the urinary rhythm to an abnormal time routine is an uncommon occurrence. In nearly all the subjects on all three time-scales, the intrinsic 24-hr. excretory rhythm persisted to a greater or lesser degree, and in some it was maintained unimpaired for the whole duration of the experiment. Subjects who failed to become adapted to the environmental time routine showed signs of stress, particularly at those times when their excretory rhythms became greatly disorganized. In at least three subjects on the 1955 expedition, the disorganization of their exeretory rhythms was peculiarly complex, in that a complete dissociation occurred between the rhythms of the excretion of water and of potassium. Further evidence for the dissociation of physiological rhythms was provided by the body-temperature recordings; in all subjects on both $21-\mathrm{hr}$. and $27 \mathrm{hr}$. routines, the bodytemperature rhythm appeared to become adapted rapidly and completely to the environmental routine, irrespective of the degree of adaptation manifested by the exeretory rhythms.

These experiments provide evidence for the persistence of the intrinsic, 24-hr. rhythm of kidney function in some human subjects; they also indicate that the mechanism which controls the normal diurnal variations in body temperature is not the same as that controlling the excretory rhythm.

Dr. J. P. Masterton, who was the medical officer on the British North Greenland Expedition and collaborated with Dr. Lewis in the physiological work, read a paper on "Nutrition and Energy Expenditure during a Polar Expedition".

There is still a lively controversy on the effects of temperature on food intake and food requirements. Investigations during the Second World War showed that the consumption of food by American soldiers rose as the temperature fell, and there appeared to be an inverse linear relationship between the two. Recent investigations of the diet of Eskimo and other inhabitants of arctic Canada and Alaska show that the calorie intake in cold countries may be little different from that in temperate countries. There have been only a few measurements made of energy expenditure in polar regions, so knowledge of food requirements is largely based on the accumulated experience of different expeditions.

Dr. Masterton measured the food intake of four men during the winter when they were living in the base hut. 'The daily individual intake was recorded for two periods of one week each, with a month's interval between the two weeks. A diary was kept of the activities of the subjects during these experimental periods, and from this, together with the measured basal metabolic rate, the energy expenditure was computed. There were wide daily variations both of expenditure and intake during this period, the range being 1,990-8,760 Calories consumed, with a mean value of 3,908 . Expenditure varied from 2,220 to 5,890 Calories, the average being 3,510 .

According to these calculations, the men were in positive food balance, and this finding is supported by the result of the measurements of body-weight, 
which showed substantial increases during the winter. Food was not limited at the base hut, and substantial snacks could be prepared by individuals apart from the regular meals.

The same subjects were out sledging for prolonged periods during the spring, and measurements were made of intake and expenditure during ten days. A high-calorie ration was provided; but the possibility of supplementing this was limited. The intake was much more constant, the range of forty observations being 4,000-5,500 Calories, with a mean of 4,800 . Expenditure, on the contrary, varied much more, as weather on occasions prevented sledging, and a whole day would have to be spent in the tent; the range was $2,230-7,670$ with a mean of 4,950. There was loss of weight during these long sledging journeys, which is consistent with the estimated negative calorie balance.

Although it is not possible on the basis of these results to be dogmatic about the effects of cold on food intake, they form a valuable basis for future work. A mean daily calorie expenditure of nearly 5,000 Calories represents very hard work, and it will be of great interest to have accurate metabolic measurements.

A food intake of 3,900 Calories in the base hut is also high, although not so high as some predictions of the effect of cold might indicate.

Dr. Masterton started his measurements because it was noted that the huskies ate human fæces voraciously in spite of the apparently adequate diet provided for them. It was considered possible that there might be a considerable excretion of fat in the fæces, in view of the high fat content of the diet both at base and while sledging. Analysis of the freces showed, however, that the fat content was low, so the reason for this dietary habit of the dogs remains unexplained. There are a number of problems concerning the nutrition and energy expenditure of huskies which have not been previously studied. Mr. Julian Taylor described briefly some of the work he had done during the past two years while he was a member of the Falkland Islands Dependencies Survey, and specially studied dog physiology. He calculated energy expenditure during sledging by measuring the pull exerted, and recorded bodyweight changes together with the food intake. Although the food consumption was high, being of the order of 2,800-3,000 Calories per day, there was considerable loss of weight during long journeys. Mr. Taylor estimated that the energy output was of the order of 4,000 Calories per day. This is a very large figure, as the weight of the dogs was of the order of $90 \mathrm{lb}$. Examination of the frees showed that there was relatively poor utilization of the diet. Mr. Taylor emphasized the need for further studies on the physiology of husky dogs, and pointed out that dog teams still play an essential part in polar travel.

Studies on acclimatization to cold were presented by Dr. Paul Massey, who acted as medical officer for the Falkland Islands Dependencies Survey. He used Mackworth's $V$ test for measuring changes in local acclimatization to cold in the fingers. By means of this test, the tactile discrimination of the finger is measured before and after the standard exposure to cold, and Dr. Mackworth has shown that there is a diminishing loss of finger numbness during repeated exposure of subjects in a cold chamber. Dr. Massey was able to study members of the Falkland Islands Dependencies Survey on Graham Land, some of whom were newcomers and others who had already spent a year or more in the Antarctic. Initially there was a marked difference between the two groups, those with antarctic experience having a much smaller loss of sensation in the finger after exposure to cold. This difference diminished during the first six weeks in Graham Land, and thereafter there was little difference between the two groups.

These results indicate that there is a fairly rapid local adaptation to cold. However, Dr. Massey believes there is probably a longer-term adaptation, as on several occasions there was mild frostbite of the exposed fingers during the test. 'These, however, only occurred in the newcomers.

Dr. Allan Rogers, who has been appointed as physiologist and medical officer to the 'Trans-Antaretic Expedition, 1955-58, described the programme of physiological research which he plans to carry out on the Expedition. He pointed out that this is a unique opportunity for physiological investigations, as the journey itself will probably occupy some four months and involve a considerable degree of exposure to cold. The work to be done on this expedition is a direct continuation of physiological work carried out on the British North Greenland Expedition, and has been planned with the help of the Medical Research Coun. cil. It is not possible to carry out elaborate experiments, for the working conditions during the crossing will be difficult, and the physiologist will also act as medical officer and dentist and will have the responsibility of veterinary work for dog teams. No heavy or bulky apparatus can be taken, as food and fuel will occupy almost the whole of the available space during the crossing.

In view of the practical importance and theoretical interest of the effect of cold on food intake and energy expenditure, the main investigation on the fifteen members of the Expedition will be an attempt to make an energy balance. Dr. Rogers will be taking with him an instrument designed by $\mathrm{H}$. S. Wolff-the integrating motor pneumotachograph-. for the measurement of oxygen consumption. The advantage of this apparatus is that it can be worn for long periods of time without interfering with the activity of the subject, and it has been so modified that it can be used at low temperatures. It is hoped that the members of the Expedition will be able to keep detailed diaries recording their activities, including hours of sleep, and also of clothing worn. Such diaries have been kept on other expeditions, and although the information so far obtained is not sufficiently systematic, it does indicate that the amount of clothing worn in the cold diminishes with prolonged life at high latitudes. This is certainly suggestive of adaptation to cold.

The experience which has been gained in the past few years by members of the Medical Research Council in developing physioiogical work on ex. peditions has shown that there are three important points to be realized : (1) that physiology must be an accepted object of the expedition; this is particularly important, as at this stage systematic observations at frequent intervals are necessary; (2) such observations should be carried out or supervised by a physiologist, or a medical officer with some special training in physiology ; (3) only simple observations or experiments should be attempted; these principles were well illustrated in the case of the Trans-Antarctic Expedition, in which physiology is, thanks to the enthusiasm of Dr. V. Fuchs, an accepted object of the Expedition, and an experienced physiologist has been appointed. O. G. EDHoLM 